\title{
HIV as a Chronic Disease: Are Primary Care Physicians Ready?
}

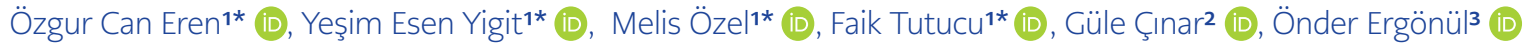 \\ 1 Koç University School of Medicine, İstanbul, Turkey \\ 2 Department of Infectious Diseases and Clinical Microbiology, Ankara University School of Medicine, Ankara, Turkey \\ 3 Department of Infectious Diseases and Clinical Microbiology, Koç University School of Medicine, İstanbul, Turkey \\ * These authors share first authorship
}

\begin{abstract}
Objective: As HIV infection is becoming a chronic entity, the role of primary care physicians (PCPs) in diagnosis and treatment is getting more significant. We aimed to assess the attitude and competency of the PCPs about HIV infection compared to other specialties and describe the areas for improvement.

Materials and Methods: A survey was conducted between 1-31 May 2017 among physicians from different specialties. The questions related to HIV infection in their clinical practice, competency, and knowledge about the transmission and preventability of the disease and their attitude towards suspected patients were asked.

Results: We included 492 physicians in the study, consisting of PCPs (32\%), infectious disease specialists (IDSs) (13\%), internal medicine specialists (IMSs) $(30 \%)$ and surgeons (25\%), practicing in 25 different cities in Turkey. When asked about HIV, $98 \%$ of IDSs considered it as a chronic disease, with 35\% thinking that it is similar to non-communicable disease (Diabetes Mellitus, Hypertension, Lymphoma). HIV was not a curable disease according to $87 \%$ of PCPs, and $21 \%$ in IDSs. The $70 \%$ of PCPs thought that HIV infection could be transmitted with vectors ( $p<0.001)$, although they self-rated their knowledge above the average. According to $34 \%$ of PCPs, HIV was transmissible through shared utensils (spoon, fork, glass), according to $50 \%$ public pools and toilets could be a source for transmission $(p<0.001)$. Upon diagnosis, only $53 \%$ of IDSs provided psychological support to patients, and this rate declined to $1 \%$ in PCPs $(p<0.001) .28 \%$ of PCPs had concerns about treating HIV patients $(\mathrm{p}<0.001)$. Conclusion: The potential role of PCPs in the follow up of HIV infected patients would be increased. However, there are significant knowledge and attitude gaps related to HIV infection among PCPs in Turkey. By thinking of increasing the role of primary care, training, and education programs should be implemented for PCPs.
\end{abstract}

Keywords: human immunodeficiency virus, primary health care, healthcare providers, training programs.

\section{INTRODUCTION}

$I^{3}$ n 2019, more than 36 million people were estimated to be harboring HIV, and the epidemic caused 39 million deaths worldwide to date (1). New adult infections have been declined by 17\% between 2007 and 2017 globally (1). Meanwhile, the incidence has an increasing trend in Turkey $(2,3)$. The current treatment strategy for HIV infecti-
Corresponding Author:

Faik Tutucu

E-mail:

ftutucu@ku.edu.tr

Received: April 28, 2020 Accepted: May 21, 2020 Published: August 31, 2020

\section{Suggested citation:}

Eren ÖC, Yigit YE, Özel M, Tutucu F, Çınar G, Ergönül Ö. HIV as a Chronic Disease: Are Primary Care Physicians Ready? Infect Dis Clin Microbiol 2020; 2: 78-90.

DOI: $10.36519 / \mathrm{idcm} .2020 .0011$ 
on is centered around antiretroviral therapy, which reduced the number of the disease attributed deaths by 48\% between 2005 and 2016 (1). Due to its manageable status, the infection was accepted and treated as a chronic disease by many physician (4).

As the HIV infection is becoming a chronic disease, physicians other than infectious disease specialists (IDSs), such as primary care physicians (PCPs), are getting more involved in the treatment and follow up process of the patients $(5,6)$. Moreover, HIV/AIDS patients need psychological support because of being discriminated against by society. The PCPs should be ready to manage the medical and psychological problems of the patients.

Previous studies showed that family physicians encounter HIV positive patients in their daily practice either in diagnosis or treatment for other diseases (5). Healthcare workers showed inadequate knowledge on HIV/AIDS (7-9). Stigmatization towards people living with HIV/AIDS among health care workers has been widely discussed in different studies (10-13). Discrimination against people living with HIV/AIDS (PLWHA) may interfere with the help-seeking behaviors of the PLWHA (14-16). Turkey has a limited number of documented data to assess the medical specialists' ethical and medical behaviors towards PLWHA. Thus, the significance of discrimination and its contributing factors is questionable. Recent studies addressed the discriminative behavior of healthcare workers due to a lack of experience and knowledge $(17,18)$. This study aimed to assess the attitude and competency of the PCPs about HIV infection compared with other specialties and describe the areas for improvement.

\section{METHODS}

\section{Study population and survey}

An online survey via Software Qualtrics consisting of 41 questions was conducted between 1-31 May 2017 among physicians from different specialties. The survey consisted of demographic information and three main parts: HIV infection in physicians' clinical practice, knowledge about the transmission and preventability of the disease, and personal attitude towards HIV positive patients. In the first part of the survey, eight questions were asked physi- cians to determine how frequently they encounter HIV positive patients, sources they apply to update their information about HIV, and the algorithm they use with HIV positive patients. The second part of the survey focused on the theoretical knowledge of the participants. Thirteen statements were given about HIV infection and its transmission routes. Participants were asked to choose "True", "False" or "I do not know" for each statement. In the third and last part of the survey, 15 statements were given to participants. We wanted them to consider each statement as "I do not have an idea", "I strongly disagree", "I somewhat disagree", "I neither agree nor disagree", "I somewhat agree", or "I strongly agree". In this part, we aimed to determine physicians' attitudes towards HIV positive or HIV suspected patients.

\section{Data Analysis}

T-test for the continuous variables and chi-square test for the categorical variables were used.

In the analysis of the second part, the questions measuring HIV knowledge, we gave +1 for each correct answer, -1 for each wrong answer, and 0 for blank ones, and calculated a final score out of 10.0 for each participant.

Each statement was evaluated separately in the analysis of the last part. The percentage of participants choosing one of the statements "I do not have an idea", "I strongly disagree", "I somewhat disagree", "I neither agree nor disagree", "I somewhat agree", or "I strongly agree" was calculated among the groups of specialties. The signif-

\section{HIGHLIGHTS}

- The role of primary care physicians in the diagnosis and treatment of HIV is getting more significant.

- There are knowledge gaps regarding HIV transmission and treatment, which might cause low-quality care due to prejudice towards HIV patients.

- These gaps can be prevented with targeted training programs for healthcare providers. 
Table 1. Key findings from the survey are summarized

7\% of PCPs thought HIV can be transmitted by coughing and sneezing.

34\% of PCPs thought HIV is transmissible by sharing forks, spoons and drinking glasses.

$50 \%$ of PCPs thought HIV can be transmitted through usage of public toilets and swimming pools.

$64 \%$ of PCPs thought HIV can be transmitted through insect bites (mosquito, etc.).

$\mathbf{8 3} \%$ of PCPs know that there is no vaccine for HIV currently.

icant threshold for P-value was set as $<0.05$. Only the significant values were taken into consideration. All statistical analyses were performed with the use of STATA software (16v, Texas, USA).

\section{RESULTS}

\section{Demographics}

From 25 different cities in Turkey, 492 physicians, including PCPs (32\%), IDSs (13\%), Internal Medicine Specialists (IMSs) (30\%), and surgeons (25\%) responded to the survey. The physicians' average duration of clinical practice was 16.2 years. Their mean age was 41, ranging between 27 and 60 .

\section{Level of Knowledge}

90\% of PCPs self-rated their knowledge about HIV as "none" or "low". On the other hand, this applied for only $10 \%$ of the IDSs. According to the knowledge scale, IDSs were ranked first (average of $9.3 / 10)$, and followed by surgeons (8.0/10) and IMSs (7.0/10). Meanwhile, PCPs got 6.2/10. Key findings are summarized in Table 1 . In a separate question, participants were asked about their competency to diagnose and treat HIV patients. Compared to $85 \%$ of IDSs, only $9 \%$ of PCPs considered themselves "medium/average or above".

\section{Clinical Practice: Diagnosis and Management}

In 2016, 20\% of PCPs encountered at least $1 \mathrm{HIV}$ patient every month in their clinical practice. 23\% of PCPs agreed on the statement: "Nowadays HIV is a chronic disease." This value approached $98 \%$ in IDSs. In another question, we asked with which disease they correlate HIV infection specifically. While $70 \%$ of PCPs could not find any similarity with another disease, $35 \%$ of IDSs thought it is similar to non-communicable diseases like hypertension, diabetes, and lymphoma. Further details on this question can be seen in Figure 1. According to $54 \%$ of PCPs and $1.5 \%$ of IDSs, the average life expectancy of an HIV patient was less than ten years.

Overall, $81 \%$ of physicians agreed that an HIV patient needs more attention than another patient with chronic disease. Only $1 \%$ of PCPs and $53 \%$ of IDSs stated that they provided psychological support to their patients. $6 \%$ of PCPs explain the treatment methods to diagnosed patients before referring them to a specialist, while $92 \%$ of IDSs do so. None of the PCPs received specific education about the explanation of the infection, although they encountered at least one HIV patient every month. All of them reported difficulty in explaining the situation to the patient upon the diagnosis/ascertainment of the disease. However, 78\% of IDSs received specific education, and $69 \%$ mentioned they do not have any difficulty in explaining the patient's situation. Questioned about the healthcare center they were working, the majority of the PCPs reported inadequacy regarding diagnosis (97\%) and treatment (98\%). In IDSs, these values were $39 \%$ and $31 \%$, respectively.

\section{Attitude and Ethical Concerns}

Physicians were found to be distressed about treating HIV patients in several aspects. $36 \%$ of PCPs were afraid of getting infected when examining patients. Similarly, 61\% reported distress about infecting their family members after treating patients. 22\% did not feel comfortable if their colleagues or other patients were informed about him/her treating HIV patients. Among IDSs, the incidence did not exceed $5 \%$ for any of these questions. Demonstrating/describing the relationship between HIV patients and 


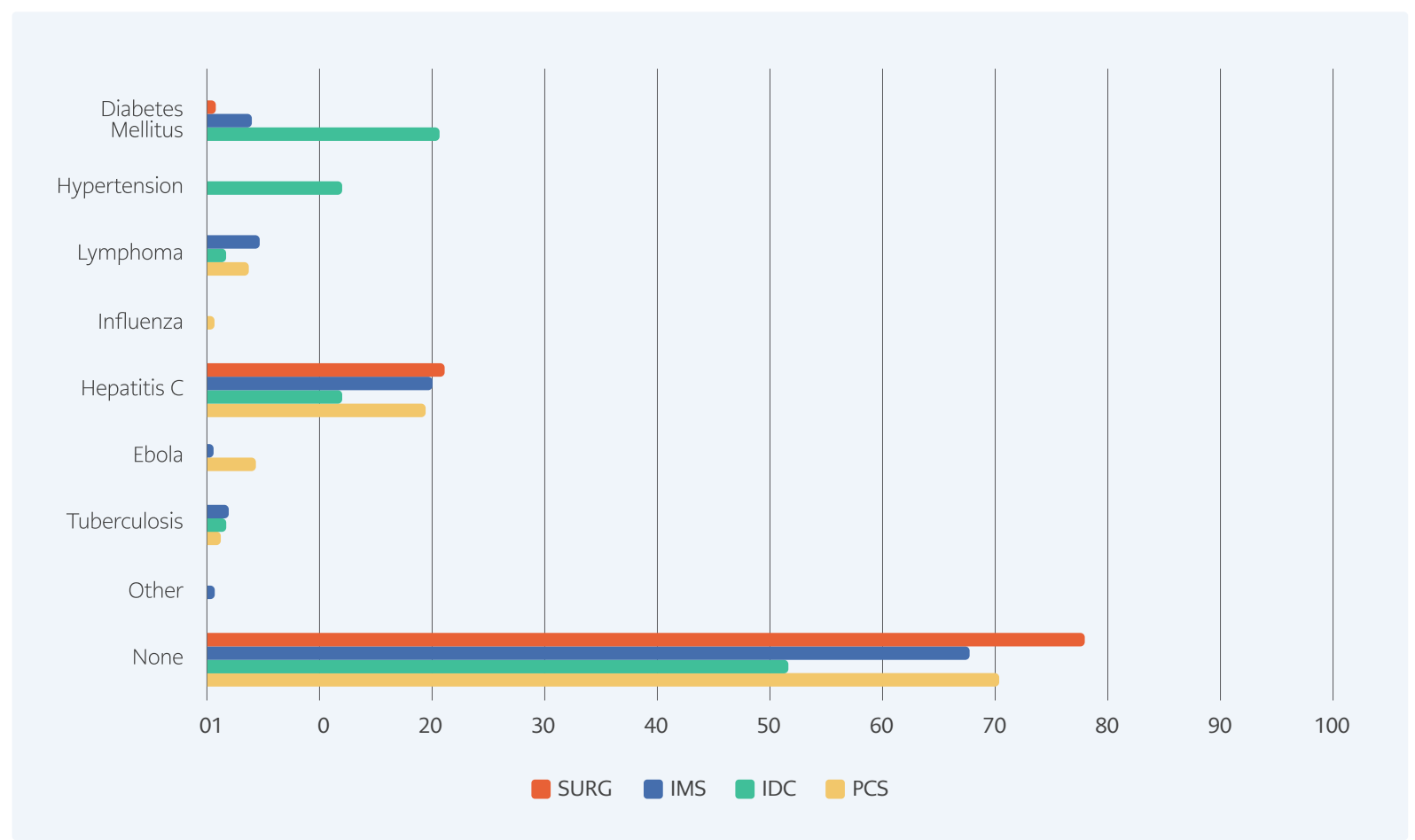

Figure 1. "With which disease do you correlate HIV when you explain to patients?"

their caregivers from an ethical perspective, the percentages of participants that agreed with each statement are summarized in Table 2.

\section{DISCUSSION}

Being the first admission place, PCPs should be competent for the assessment of an HIV patient. 90\% of PCPs who considered themselves inadequate in terms of knowledge and $69 \%$ of the rest were proven to do wrong even in questions like whether HIV can be transmitted through vectors. Considering these physicians self-rated their knowledge as medium or higher about the transmission of the disease, and 56\% saw at least one patient per month, education appeared to be essential. As 17\% of PCPs thought there was a vaccine available for HIV, the patients seem far from receiving appropriate treatment options.

IDSs managed more HIV patients in their clinical practice and were more aware of the disease's facts, as shown in our scale, and they treated the disease as a chronic condition. IDSs might have associated HIV, especially diabetes and hypertension because they are chronic, controllable, and not fatal. Consequently, for HIV positive people, the average life expectancy of the majority of IDSs exceeded 20 years.

PCPs, who encountered fewer patients in practice, did not tend to associate HIV with any other disease. The rest associated the disease with Hepatitis $\mathrm{C}$ and Ebola because they had similar transmission ways (iv drug use and sexual transmission) and high mortality. Since the latter is rather contagious, PCPs overestimated the transmission of HIV. More than 50\% mentioned that life expectancy for HIV patients did not exceed ten years, possibly because they were unaware of the current treatment $(19,20)$.

Although $81 \%$ of all physicians in our study agreed that an HIV patient required much more attention, they did not reflect this in their clinical practice. For instance, most PCPs and IDSs did not provide psychological support after diagnosis or explain treatment alternatives. These are the weaknesses of the healthcare system and needs urgent improvement.

We found that $28 \%$ of PCPs and $21 \%$ of surgeons preferred not treating HIV patients if they had the 
Table 2. Statements indicating ethical concerns

\begin{tabular}{|c|c|c|c|c|}
\hline Statements & PCPs & IDSs & IMSs & SRGs \\
\hline "Under certain conditions an HIV test can be applied to a patient without his/her knowledge." & $95 \%$ & $69 \%$ & $78 \%$ & $99 \%$ \\
\hline $\begin{array}{l}\text { " Relatives (parents/partner/children) of the patient should be informed about the test results of the } \\
\text { patient without his/her knowledge." }\end{array}$ & $95 \%$ & $59 \%$ & $78 \%$ & $99 \%$ \\
\hline "I do not prefer to treat HIV patients." & $28 \%$ & $0 \%$ & $8 \%$ & $21 \%$ \\
\hline "HIV patients acquired infection because of mistakes they made." & $7 \%$ & $4 \%$ & $7 \%$ & $2 \%$ \\
\hline $\begin{array}{l}\text { "HIV+ patients having treatment cannot go back to their early life standards (change in life } \\
\text { expectancy, life style, quality of life, health status)." }\end{array}$ & $90 \%$ & $11 \%$ & $70 \%$ & $88 \%$ \\
\hline "A patient on HIV treatment will experience discrimination in society." & $88 \%$ & $64 \%$ & $76 \%$ & $92 \%$ \\
\hline
\end{tabular}

PCPs: Primary Care Physicians; IDSs: Infectious Disease Specialists; IMSs: Internal Medicine Specialist; SRGs: Surgeons

opportunity to abstain. This could be related to the lack of knowledge about the transmission of the disease, detected by our knowledge scale. IDSs and IMSs, having more profound knowledge, had significantly lower rates of preference for avoiding HIV patients. Physician's education seems to be the main determining factor from this aspect. In previous studies, additional training for healthcare workers was reported to decrease the stigmatization of HIV patients (21-23).

Most of the IDSs stated that "Under certain conditions, an HIV test can be applied to a patient without his/her knowledge.", however like other infectious diseases such as influenza, hepatitis C or tuberculosis, HIV tests cannot be performed without the consent of the individual.

\section{Limitations \& Future Aspects}

The sample size could be larger; however, our significant findings are sufficient to describe Turkey's situation. In terms of knowledge and attitude, we detected a dramatic picture of active physicians. However, since the responders could be the ones who have a higher interest in the topic, the real situation could be even worse.
Considering problems stemming from a lack of knowledge and ethical misconduct, we believe medical and deontological training as the sole solution. Especially transmission ways and treatment strategies should be focused on during the training.

\section{CONCLUSION}

Since the incidence of HIV is increasing significantly in Turkey, PCPs will encounter more HIV positive patients in the future. Taking the importance of primary care into consideration, the role of PCPs as being able to diagnose HIV positive patients is increasing. However, there are significant knowledge and attitude gaps related to HIV infection among PCPs in Turkey. Therefore, special training and education programs should be implemented for PCPs. This study also suggests that the in-depth psychological approach of physicians should be improved. This approach is vital for the management of HIV positive patients because society is prone to have prejudices about the patients. Prejudices affect both the life quality of the patients and also their treatment efficiency. Therefore, physicians need to gain a more professional attitude. 
Peer-review: Externally peer-reviewed

Author Contributions: Concept - O.C.E., Y.E.Y., M.Ö., F.T., G.Ç., Ö.E.; Design - Ö.E.; Supervision - Ö.E. G.Ç.; Fundings - Ö.E. G.Ç.; Data Collection and/or Processing - O.C.E., Y.E.Y., M.Ö., F.T.; Analysis and/ or Interpretation - O.C.E., Y.E.Y., M.Ö., F.T.; Literature Review - O.C.E., Y.E.Y., M.Ö., F.T.; Writer - O.C.E.,Y.E.Y., M.Ö., F.T.; Critical Reviews - Ö.E.

\section{REFERENCES}

1 Pandey A, Galvani AP. The global burden of HIV and prospects for control. Lancet HIV 2019; 6: e809-e811.

2 Sargin F, Goktas S. HIV prevalence among men who have sex with men in Istanbul. Int J Infect Dis 2017; 54: 58-61.

3 Turkish Republic Ministry of Health General Directorate of Public Health HIV/AIDS Control Program (2019-2024), 1131, Ankara, 2019.

4 Deeks SG, Lewin, SR, Havlir DV. The end of AIDS: HIV infection as a chronic disease. Lancet 2013; 382: 1525-33.

5 Kendall CE, Manuel DG, Younger J, Hogg W, Glazier RH, Taljaard M. A population-based study evaluating family physicians' HIV experience and care of people living with HIV in Ontario. Ann Fam Med 2015; 13: 436-445.

6 Morales Rodriguez K, Khalili J, Trevillyan J, Currier J. What Is the Best Model for HIV Primary Care? Assessing the Influence of Provider Type on Outcomes of Chronic Comorbidities in HIV Infection. J Infect Dis 2018; 218: 337-9.

7 Buskin SE, Li L, Yin H, Yu T, McGough JP. HIV/AIDS knowledge and attitudes in Chinese medical professionals and students before and after an informational lecture on HIV/AIDS. J Public Health Manag Pract 2002; 8: 38-43.

8 Bares S, Steinbeck J, Bence L, Kordik A, Acree ME, Jih J, et al Knowledge, attitudes, and ordering patterns for routine HIV screening among resident physicians at an urban medical center. J Int Assoc Provid AIDS Care 2016; 15: 320-7.

9 Quach L, Mayer K, McGarvey ST, Lurie MN, Do P. Knowledge, attitudes, and practices among physicians on HIV/AIDS in Quang Ninh, Vietnam. AIDS Patient Care STDS 2005; 19: 335-46.

10 Hedayati-Moghaddam MR, Moradi Marjaneh M, Mashhadi IE. Knowledge and attitudes of physicians in private practice towards HIV/AIDS in Mashhad, Iran. Int J STD AIDS 2012; 23:e11-e16.

11 Mahfouz AA, Alakija W, al-Khozayem AA, al-Erian RA. Knowledge and attitudes towards AIDS among primary health care physicians in the Asir Region, Saudi Arabia. J R Soc Health 1995; 115:23-5.

12 Fido A, Al Kazemi R. Survey of HIV/AIDS knowledge and attitudes of Kuwaiti family physicians. Fam Pract 2002; 19: 682-4.
Conflict of Interest: The authors have no conflict of interest to declare.

Financial Disclosure: The authors declared that this study has received no financial support.

Acknowledgements: The authors would like to thank KLIMIK (Turkish Society of Clinical Microbiology and Infectious Diseases) for their support.
13 Lui PSC, Sarangapany J, Begley K, Coote K, Kishore K. Medical and nursing students perceived knowledge, attitudes, and practices concerning human immunodeficiency virus. ISRN Public Health 2014.

14 Alemu T, Biadgilign S, Deribe K, Escudero HR. Experience of stigma and discrimination and the implications for healthcare seeking behavior among people living with HIV/AIDS in resource-limited setting. SAHARA J 2013; 10: 1-7.

15 Wagner AC, Girard T, McShane KE, Margolese S, Hart TA. HIV-Related Stigma and Overlapping Stigmas Towards People Living With HIV Among Health Care Trainees in Canada. AIDS Educ Prev 2017; 29: 364-76.

16 Umeh CN, Essien EJ, Ezedinachi EN, Ross MW. Knowledge, beliefs and attitudes about HIV/AIDS-related issues, and the sources of knowledge among health care professionals in southern Nigeria. J R Soc Promot Health 2008; 128: 233-9.

17 Duyan V, Agalar F, Sayek I. Surgeons' attitudes toward HIV/ AIDS in Turkey. AIDS Care 2001; 13: 243-250.

18 Koç A, Öztaş D, Ceylan E. Correlation of misperceptions in Turkish nurses' knowledge regarding HIV and their attitude toward patients with HIV/AIDS. Med J Islamic World Acad Sci 2017; 25: 81-88.

19 Thomson M, Konerman MA, Choxi H, Lok AS. Primary care physician perspectives on hepatitis $C$ management in the era of direct-acting antiviral therapy. Dig Dis Sci 2016; 61: 3460-8.

20 Kohli A, Shaffer A, Sherman A, Kottilil S. Treatment of hepatitis C: a systematic review. JAMA 2014; 312: 631-40.

21 Hossain MB, Kippax S. HIV-related discriminatory attitudes of healthcare workers in Bangladesh. J Health Popul Nutr 2010; 28: 199-207

22 Stringer KL, Turan B, McCormick L, Durojaiye M, Ntblade L, Kempf MC, et al. HIV-Related Stigma Among Healthcare Providers in the Deep South. AIDS Behav 2016; 20: 115-25.

23 Nyblade L, Srinivasan K, Mazur A, Raj T, Patil DS, Devadass D, et al. HIV Stigma Reduction for Health Facility Staff: Development of a Blended- Learning Intervention. Front Public Health 2018; 6: 165. 


\section{SUPLEMENTARY MATERIAL: SURVEY QUESTIONS}

\section{HIV/AIDS Survey}

Dear Colleague, As the Public Health Department of Koç University School of Medicine, we prepared the survey below to determine the knowledge and needs of primary care specialists about HIV/AIDS. The survey is composed of 4 parts and 41 questionnaires. 5-10 minutes will be enough to answer all questions. We assure you that your answers will be recorded anonymously, and no personal data will be revealed. The results of this survey will be used to determine the concept of educations that will be held in cooperation with Turkish Clinical Microbiology and Infectious Diseases Foundation (KLIMIK).

\section{Participant Demographics}

Q1 Birth Date:

Q2 Years of experience:

Q3 Gender

$\bigcirc$ Male (1)

$\bigcirc$ Female (2)

Q4 Specialty:

$\bigcirc$ Family care physician (1)

$\bigcirc$ Other (please specify): (2)

Q5 Where do you live?

Part 1: HIV/AIDS in your clinical practice

Q6 How often do you care for HIV positive patients in a month?
$\bigcirc \quad 0$ (1)
○ $1(2)$
O $2-5(3)$
O $5-10(4)$
○ $10+(5)$

Q7 How would you rate your level of knowledge about HIV?

$\bigcirc$ None (1)

$\bigcirc$ Low (2)

$\bigcirc$ Medium (3)

$\bigcirc$ High (4)

Very High (5) 
Q8 How confident are you in your ability to diagnose and treat HIV?

$\bigcirc$ Not at all confident (1)

$\bigcirc$ Not very confident (2)

O Neutral (3)

$\bigcirc$ Somewhat confident (4)

$\bigcirc$ Very confident (5)

Q9 When you are uncertain about diagnosis and treatment issues related to HIV, what information sources do you use? (You can choose multiple choices.)

$\bigcirc$ None (1)

$\bigcirc$ Infectious disease specialist (2)

$\bigcirc$ Internet and online sources (3)

$\bigcirc$ Help line (4)

$\bigcirc$ Literature (5)

$\bigcirc$ Other (please mention): (6)

Q10 Do you explain the treatment methods to diagnosed patients before referring them to a specialist?

$\bigcirc$ Yes (1)

O No (2)

Other (please specify) (3)

Q11 Have you had a specific education about how to explain the infection? (If you have, please mention.)

$\bigcirc$ No (1)

$\bigcirc$ Yes (2)

Q12 With which disease do you correlate HIV when you explain to patients?

$\bigcirc$ Diabetes (1)

$\bigcirc$ Ebola (2)

Hypertension (3)

$\bigcirc$ Hepatitis C (4)

$\bigcirc$ Influenzas (5)

Tuberculosis (6)

- Lymphoma (7)

$\bigcirc$ Other (please specify) (8)

O None (9)

Q13 Do you provide psychological support to your patients during and after the treatment? (If yes, please specify such as case management, patient education programs, support groups, cognitive behavioral theory.

$\bigcirc$ Yes (1)

No (2) 
Part 2: Information about HIV infection and its transmission

Q14 What do you think is the average life expectancy for people living with HIV from the time of diagnosis?
O $0-5(1)$
○ $5-10(2)$
O $10-15(3)$
O $12-20(4)$
○ $20+(5)$

Q15 HIV/AIDS is not a treatable disease.

O True (1)

$\bigcirc$ False (2)

I I don't know (3)

Q16 HIV/AIDS can only be transmitted by sexual intercourse.

O True (1)

O False (2)

I don't know (3)

Q17 HIV/AIDS can be transmitted by unprotected sexual intercourse.

O True (1)

False (2)

I don't know (3)

Q18 HIV/AIDS can be transmitted by handshaking or hugging.

$\bigcirc$ True (1)

False (2)

I don't know (3)

Q19 HIV/AIDS can be transmitted by coughing or sneezing.

$\bigcirc$ True (1)

$\bigcirc$ False (2)

I don't know (3)

Q20 HIV/AIDS can be transmitted by sharing a fork, a spoon or a drinking glass.

$\bigcirc$ True (1)

○ False (2)

I don't know (3) 
Q21 HIV/AIDS can be transmitted through swimming pool or toilet.

$\bigcirc$ True (1)

$\bigcirc$ False (2)

I don't know (3)

Q22 HIV/AIDS can be transmitted through mosquito and insect bite.

$\bigcirc$ True (1)

$\bigcirc$ False (2)

I don't know (3)

Q23 HIV/AIDS can be transmitted from mother to child during pregnancy and childbirth.

$\bigcirc$ True (1)

$\bigcirc$ False (2)

I don't know (3)

Q24 HIV/AIDS can be transmitted by breastfeeding.

O True (1)

$\bigcirc$ False (2)

$\bigcirc$ I don't know (3)

Q25 HIV vaccine can protect against HIV disease.

$\bigcirc$ True (1)

$\bigcirc$ False (2)

I don't know (3)

Q26 HIV/AIDS is a disease of only homosexuals.

$\bigcirc$ True (1)

$\bigcirc$ False (2)

○ I don't know (3)

Part 3: Please mark to what extent you agree or disagree with the following

Q27 Nowadays HIV is a chronic disease.

$\bigcirc \quad 0: I$ do not have an idea (1)

1:I strongly disagree (2)

○ 2:I somewhat disagree (3)

$\bigcirc \quad$ 3:I neither agree nor disagree (4)

4:I somewhat agree (5)

5:I strongly agree (6)

Q28 An HIV positive patient needs more attention when compared with an average chronic patient.

$\bigcirc$ 0:I do not have an idea (1)

- 1:I strongly disagree (2)

$\bigcirc$ 2:I somewhat disagree (3) 


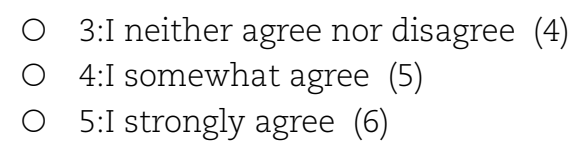

Q29 I find it difficult to explain his/her situation to the patient when his/her diagnosis becomes certain.

0:I do not have an idea (1)

0 1:I strongly disagree (2)

○ 2:I somewhat disagree (3)

$\bigcirc \quad$ 3:I neither agree nor disagree (4)

4:I somewhat agree (5)

5:I strongly agree (6)

Q30 I'm afraid of getting infected when I treat an HIV+ patient.

O $0: I$ do not have an idea (1)

1:I strongly disagree (2)

2:I somewhat disagree (3)

$\bigcirc$ 3:I neither agree nor disagree (4)

4:I somewhat agree (5)

5:I strongly agree (6)

Q31 After treating an HIV+ patient, I'm afraid of infecting my family and people with whom I am in close contact.

O:I do not have an idea (1)

1:I strongly disagree (2)

$\bigcirc$ 2:I somewhat disagree (3)

$\bigcirc$ 3:I neither agree nor disagree (4)

○ 4:I somewhat agree (5)

5:I strongly agree (6)

Q32 Under certain conditions an HIV test can be applied to a patient without his/her knowledge.

0 0:I do not have an idea (1)

○ 1:I strongly disagree (2)

2:I somewhat disagree (3)

3:I neither agree nor disagree (4)

- 4:I somewhat agree (5)

5:I strongly agree (6)

Q33 Relatives (parents/partner/children) of the patient should be informed about the test results of the patient without his/her knowledge.

$\bigcirc \quad$ 0:I do not have an idea (1)

- 1:I strongly disagree (2)

○ 2:I somewhat disagree (3)

$\bigcirc \quad$ 3:I neither agree nor disagree (4)

$\bigcirc$ 4:I somewhat agree (5)

5:I strongly agree (6) 
Q34 I do not prefer to treat HIV+ patients.

0 0:I do not have an idea (1)

- 1:I strongly disagree (2)

$\bigcirc$ 2:I somewhat disagree (3)

- 3:I neither agree nor disagree (4)

$\bigcirc$ 4:I somewhat agree (5)

5:I strongly agree (6)

Q35 It bothers me if my other patients know that I have HIV+ patients.

0 0:I do not have an idea (1)

$\bigcirc \quad$ 1:I strongly disagree (2)

○ 2:I somewhat disagree (3)

$\bigcirc \quad$ 3:I neither agree nor disagree (4)

$\bigcirc$ 4:I somewhat agree (5)

5:I strongly agree (6)

Q36 Diagnosis/diagnostic opportunities are not sufficient in the healthcenter I work.

0:I do not have an idea (1)

1:I strongly disagree (2)

$\bigcirc$ 2:I somewhat disagree (3)

$\bigcirc$ 3:I neither agree nor disagree (4)

- 4:I somewhat agree (5)

5:I strongly agree (6)

Q37 Treatment opportunities are not sufficient for the HIV+ patients in the health center I work.

0 0:I do not have an idea (1)

1:I strongly disagree (2)

$\bigcirc$ 2:I somewhat disagree (3)

$\bigcirc$ 3:I neither agree nor disagree (4)

4:I somewhat agree (5)

5:I strongly agree (6)

Q38 I would like to work in health centers that are specialized for HIV.

O $0:$ I do not have an idea (1)

○ 1:I strongly disagree (2)

○ 2:I somewhat disagree (3)

$\bigcirc \quad$ 3:I neither agree nor disagree (4)

$\bigcirc$ 4:I somewhat agree (5)

5:I strongly agree (6)

Q39 HIV+ patients having treatment cannot go back to their early life standards (change in life expectancy, life style, quality of life, health status).

0 0:I do not have an idea (1)

$\bigcirc \quad$ 1:I strongly disagree (2)

○ 2:I somewhat disagree (3)

○ 3:I neither agree nor disagree (4)

- 4:I somewhat agree (5)

5:I strongly agree (6) 
Q40 A patient on HIV treatment will experience discrimination in society.

O 0:I do not have an idea (1)

1:I strongly disagree (2)

$\bigcirc$ 2:I somewhat disagree (3)

$\bigcirc \quad$ 3:I neither agree nor disagree (4)

4:I somewhat agree (5)

5:I strongly agree (6)

Q41 HIV+ patients acquired infection because of mistakes they made.

0 0:I do not have an idea (1)

- 1:I strongly disagree (2)

$\bigcirc$ 2:I somewhat disagree (3)

○ 3:I neither agree nor disagree (4)

○ 4:I somewhat agree (5)

5:I strongly agree (6) 